\title{
PERCEPATAN KEMAMPUAN BERAKAR DAN PERKEMBANGAN AKAR STEK PUCUK Shorea platyclados MELALUI APLIKASI ZAT PENGATUR TUMBUH IBA
}

Acceleration of rooting ability and root development of Shorea platyclados shoot cutting through application of IBA hormone

\author{
Suryo Hardiwinoto ${ }^{1}$, Rixa Riyanti ${ }^{1}$, Widiyatno ${ }^{1}$, Adriana ${ }^{1}$, Widaryanti Wahyu Winarni ${ }^{1}$, \\ Handojo Hadi Nurjanto ${ }^{1}$, dan Eko Priyo ${ }^{2}$ \\ ${ }^{1}$ Fakultas Kehutanan, Universitas Gadjah Mada \\ Jl. Agro No. 1, Bulaksumur, Sleman, Yogyakarta, Indonesia \\ email: suryohadiwinoto@yahoo.com \\ ${ }^{2} \mathrm{PT}$. Sari Bumi Kusuma \\ Jl. Adisucipto Km. 5,3 Pontianak, Kalimantan Barat, Indonesia
}

Tanggal diterima: 4 Januari 2016, Tanggal direvisi: 18 Januari 2016, Disetujui terbit: 27 Juni 2016

\begin{abstract}
Shorea platyclados is one of fast growing Dipterocarp species for enrichment planting in Logged Over Area (LOA) of tropical rain forests. One of the constrain to supply the seedling for support enrichment planting is the irregular flowering of $S$. platyclados. Moreover, the vegetative propagation is an alternative method to provide the sustainable seedling for enrichment planting in the LOA. This experiment was carried out to assess the effects of IBA concentrations on rooting ability, the primary and secondary root length, and the accumulated number of primary and secondary roots on shoot cutting of $S$. platyclados. The research was conducted in Completly Randomized Design (CRD) with 5 replications. The treatment was five concentrations of IBA, i.e. 0 ppm, 25 ppm, $50 \mathrm{ppm}, 75 \mathrm{ppm}$, and $100 \mathrm{ppm}$. The data were analyzed using one-way analysis of variance (one way ANOVA) to determine the effect of IBA concentration variation among the treatments. The Duncan Multiple Range Test $(D M R T)$ was used for multiple comparisons among the means of treatment at t $\alpha=5 \%$, Results showed IBA concentrations significantly affected the rotting ability, the primary and secondary root length of shoot cutting $(P$ $<0.05)$. On the other hand, the number of primary and secondary roots was not significantly different among treatment $(P>0.05)$. For rooting ability, 100 ppm of IBA concentration was the highest of all treatments. Meanwhile, 75 ppm of IBA concentration was the best treatment for development of root, i.e. the number of primary roots, the length primary and secondary roots.
\end{abstract}

Keywords: IBA, rooting ability, root development, Shorea platyclados

\begin{abstract}
ABSTRAK
Shorea platyclados merupakan salah satu jenis fast growing meranti yang sangat potensial untuk dikembangkan sebagai tanaman pengayaan pada hutan tropis sekunder. Salah satu hambatan dalam penyediaan bibit secara generatif untuk mendorong program tersebut adalah pembungaan yang bersifat tidak teratur. Untuk itu upaya perbanyakan vegetatif merupakan suatu alternatif untuk mensuplai bahan tanaman guna penanaman pengkayaan pada hutan tropis sekunder. Tujuan penelitian ini adalah untuk mengetahui pengaruh dosis hormon IBA terhadap kemampuan berakar, panjang akar primer dan sekunder, serta jumlah akar primer dan sekunder pada stek pucuk S. platyclados. Penelitian dilaksanakan dengan rancangan Completely Randomized Design (CRD) dengan 5 ulangan. Perlakuan yang diujikan adalah 5 konsentrasi IBA, yaitu, 0 ppm, 25 ppm, 50 ppm, 75 ppm dan 100 ppm. Data yang diperoleh dianalisis dengan analisis varians satu arah (ANOVA) dan perbedaan antar perlakuan diuji dengan menggunakan Duncan Multiple Range Test (DMRT) pada t $\alpha=5 \%$. Hasil penelitian menunjukkan bahwa perbedaan konsentrasi IBA memberikan hasil yang berbeda nyata $(\mathrm{P}<0,05)$ terhadap kemampuan berakar, panjang akar primer dan panjang akar sekunder stek pucuk. Di sisi lain pemberian konsentrasi IBA pada berbagai dosis tidak memberikan efek yang berbeda terhadap variable jumlah akar primer dan sekunder $(\mathrm{P}>0,05)$. Konsentrasi IBA 100 ppm menghasilkan kemampuan berakar tertinggi, sedang konsentrasi IBA 75 ppm memberikan dampak yang optimal terhadap perkembangan akar (jumlah dan panjang akar primer serta sekunder) dibandingkan dengan perlakuan lain.
\end{abstract}

Kata kunci: IBA, kemampuan berakar, perkembangan akar, Shorea platyclados 


\section{PENDAHULUAN}

Shorea platyclados merupakan kelompok tanaman Dipterocarpaceae yang masuk dalam Genus Shorea dan dapat hidup pada ketinggian $300-1.200 \mathrm{~m} \mathrm{dpl}$, tetapi mempunyai pertumbuhan yang optimum pada ketinggian 750 - 1.000 m dpl (Appanah \& Weinland, 1993; Ashton, 1982; Newman, Burgess, \& Whitmore, 1996a, 1996b). Jenis tanaman ini banyak ditemukan di pegunungan Kalimantan, Sumatra, dan Semenanjung Malaysia. S. platyclados merupakan salah satu jenis unggulan untuk kelompok dipterocarps yang direkomendasikan untuk kegiatan penanaman pengayaan (enrichment planting) dan rehabilitasi Logged Over Area (LOA) hutan hujan tropika di Indonesia. Hal ini didasarkan pada hasil uji spesies umur 6,5 tahun di Kalimantan Tengah yang menunjukan bahwa tanaman ini mempunyai mempunyai riap dbh dan tinggi tanaman tertinggi yaitu adalah $2,56 \mathrm{~cm} /$ tahun dan $1,33 \mathrm{~m} /$ tahun (Widiyatno, Soekotjo, Naiem, Purnomo, \& Setiyanto, 2014).

Upaya penanaman pengkayaan LOA dengan menggunakan S. platyclados dalam skala yang luas akan memerlukan bibit dalam jumlah besar dengan tata waktu yang tepat. Akan tetapi upaya pengadaan bibit secara generatif dalam jumlah besar dan berkesimambungan untuk kegiatan rehabilitasi LOA menghadapi beberapa hambatan, yaitu pembungaan massal terjadi pada interval waktu yang tidak teratur antara 1-6 tahun (Numata et al., 2012; Numata, Yasuda, Okuda, Kachi, \& Noor, 2003; Subiakto, 2006), dan buahnya yang mempunyai sifat tidak bisa disimpan dalam periode yang lama (recalcitrant seed) (Sasaki, 1980). Salah satu upaya untuk mengatasi permasalahan tersebut adalah dengan perbanyakan secara vegetatif berupa stek pucuk.

Salah satu faktor yang berpengaruh terhadap keberhasilan pengakaran stek pucuk adalah adanya zat pengatur tumbuh (ZPT). ZPT dalam tanaman terdiri dari 5 kelompok yaitu auksin, sitokinin, giberelin, etilen dan inhibitor; dan di antara ZPT tersebut yang terpenting adalah auksin (Abidin, 1983). Pemberian auksin pada stek bertujuan untuk meningkatkan persentase perakaran, mempercepat pertumbuhan akar, meningkatkan jumlah dan kualitas akar yang terbentuk dan meningkatkan keseragam akar (Hartmann, Kester, \& Davies, 1990). Di antara banyak jenis auksin adalah Indole Butyric Acid (IBA) yang merupakan senyawa auksin yang paling banyak digunakan dan merupakan bentuk yang terbaik serta dianjurkan penggunaannya untuk merangsang perakaran pada stek (Hartmann \& Kester, 1983; Hunt, Trueman, \& Rasmussen, 2011).

Berkenaan dengan hal ini maka diperlukan pengembangan paket teknologi pembiakan vegetatif $S$. platyclados melalui stek pucuk untuk mendukung pengadaan bibit dalam jumlah besar dan berkesinambungan setiap tahun. Untuk itu penelitian mengenai "Percepatan Kemampuan Berakar dan Perkembangan Stek Pucuk $S$. platyclados melalui Aplikasi Zat Pengatur Tumbuh IBA" diharapkan dapat mendukung keberhasilan dan keberlangsungan program pengayaan pada areal hutan sekunder. Tujuan penelitian ini adalah untuk mengetahui pengaruh dosis hormon IBA terhadap kemampuan berakar, pertumbuhan panjang akar primer (PAP) dan sekunder (PAS), serta jumlah akar primer (JAP) dan sekunder (JAS) pada stek pucuk $S$. platyclados.

\section{BAHAN DAN METODE}

\section{A. Waktu dan tempat}

Penelitian ini dilaksanakan di Persemaian Km 53 PT. Sari Bumi Kusuma, Kalimantan Tengah. Materi stek pucuk S. platyclados yang digunakan dalam penelitian ini berasal dari kebun pangkas yang dibangun dari perbanyakan generatif (biji) hasil eksplorasi buah tahun awal 2005. Biji tersebut kemudian disemaikan di persemaian selama 8 bulan dan digunakan untuk membangun kebun pangkas pada tahun 2006, dengan jarak tanam $75 \times 75 \mathrm{~cm}$. 


\section{B. Bahan dan alat penelitian}

Penelitian dilaksanakan dengan rancangan Completly Randomized Design (CRD) dengan 5 ulangan, dimana setiap ulangan terdiri atas 5 stek pucuk. Perlakuan yang diujikan dalam penelitian ini adalah 5 konsentrasi ZPT IBA, yaitu kontrol, 0 ppm, 25 ppm, 50 ppm, 75 ppm dan 100 ppm (Gambar 1). Pengamatan dilakukan selama 2,5 bulan, dengan variabel yang diamati meliputi persen hidup, jumlah dan panjang akar primer

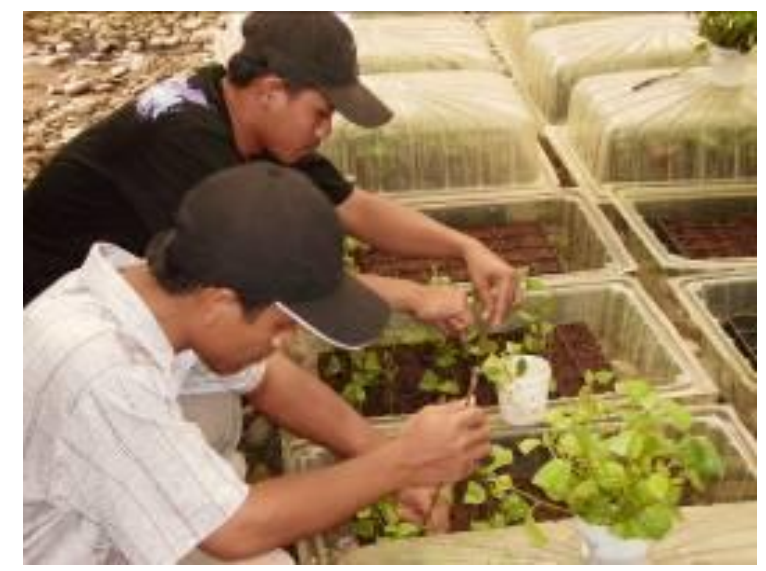

Gambar 1. Pemberian perlakuan dan penanaman pada media pengakaran

\section{HASIL DAN PEMBAHASAN}

\section{A. Kemampuan berakar, jumlah dan panjang akar primer}

Hasil ANOVA menunjukan bahwa konsentrasi IBA memberikan respon yang nyata terhadap variabel kemampuan berakar $(\mathrm{P}<0,05)$ dari stek pucuk $S$. platyclados, (Tabel 1 dan 2). Konsentrasi 100 ppm menghasilkan persen berakar tertinggi, yaitu $60 \%$, sedangkan perlakuan kontrol memberikan kemampuan berakar terendah, yaitu 20\%. Konsentrasi IBA 100 ppm pada stek pucuk S. platyclados memberikan hasil pengakaran yang lebih baik dibandingkan beberapa jenis Dipterokarpa seperti Shorea taluta, Vatica wallichii dan Anisoptera scaptula yang hanya menghasilkan pengakaran di bawah 50\% (Momose, 1978). Di sisi lain, pemberian IBA tidak berpengaruh nyata terhadap kemampuan berarakar dari stek pucuk S. leprosula (Aminah, Dick, Leakey, Grace, \&
(JAP dan PAP), serta jumlah dan panjang akar sekunder (JAS dan PAS)

\section{Analisis data}

Data yang diperoleh dianalisis dengan menggunakan one-way analysis of variance (ANOVA) dengan menggunakan software SAS 9.0. Perbedaan antar perlakuan pada taraf kepercayaan $95 \%$ dianalisis dengan Duncan Multiple Range Test (DMRT) untuk mengetahui konsentrasi IBA yang paling optimal bagi pertumbuhan akar.

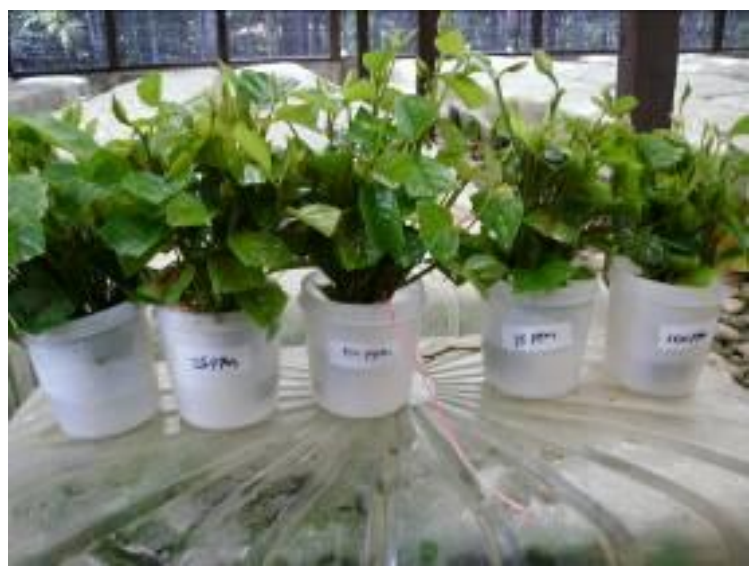

Smith, 1995; Srivastava \& Manggil, 1981) dan S. macrophylla (Lo, 1985). Hal ini mengindikasikan bahwa pemberian IBA sampai dengan konsentrasi 100 ppm tidak memberikan efek toxic dan sangat berkontribusi positif dalam menunjang kebehasilan pengakaran stek pucuk S. platyclados.

Konsentrasi IBA memberikan hasil yang berbeda nyata terhadap variabel PAP $(\mathrm{P}<0,05)$, sedangkan untuk variabel JAP tidak berbeda nyata pada taraf kepercayaan 95\% ( $\mathrm{P}>0,05$ ) (Tabel 1). Konsentrasi IBA 75 ppm memberikan JAP dan PAP tertinggi yaitu masing-masing 2,98 dan 5,68 cm (Tabel 2), sedangkan yang terendah adalah perlakuan control, yaitu 1,75 dan $2,81 \mathrm{~cm}$ masing-masing untuk PAP dan JAP. Hal ini mengindikasikan bahwa perlakuan pemberian hormon IBA menghasilkan panjang akar primer (PAP) yang lebih panjang tetapi tidak meningkatkan jumlah akar dari stek pucuk meranti, khususnya $S$. platyclados. Keadaan ini 
juga dijelaskan oleh (Hunt et al., 2011), yang menyatakan bahwa IBA tidak mempengaruhi perkembangan jumlah akar primer dari stek
Pinus elliotii var. elliotii dan P. caribeae var. Hondurensi.

Tabel 1. Anova pengaruh konsentrasi IBA terhadap kemampuan berakar stek pucuk S. platyclados

\begin{tabular}{lrrrrrrr}
\hline \multirow{2}{*}{ Sumber Variasi } & \multirow{2}{*}{$\mathrm{db}$} & \multicolumn{2}{c}{ Kemampuan Berakar $(\%)$} & \multicolumn{2}{c}{ JAP } & \multicolumn{2}{c}{ PAP } \\
\cline { 3 - 8 } & & KT & Sig. & KT & Sig. & KT & Sig. \\
\hline Konsentrasi IBA & 4 & 0,17 & $2,75^{*}$ & 1.03 & $0,76 \mathrm{~ns}$ & 13.89 & $4,45^{*}$ \\
Error & 19 & 0.06 & & 1.35 & 3.13 & \\
\hline
\end{tabular}

Ketetangan: ${ }^{*}=$ berbeda nyata pada taraf uji $\alpha$ 0,05; ns = tidak signifikan; JK = jumlah kuadrat; JAP = jumlah akar primer; $\mathrm{PAP}=$ panjang akar primer

Tabel 2. Uji lanjut pengaruh konsentrasi IBA terhadap kemampuan berakar stek pucuk S. platyclados

\begin{tabular}{llll}
\hline \multicolumn{1}{c}{ Konsentrasi IBA } & Kemampuan berakar $(\%)$ & JAP & PAP (cm) \\
\hline $100 \mathrm{ppm}$ & $0,60 \mathrm{a}$ & $2,82 \mathrm{a}$ & $4,92 \mathrm{ab}$ \\
$75 \mathrm{ppm}$ & $0,56 \mathrm{ab}$ & $2,98 \mathrm{a}$ & $5,68 \mathrm{a}$ \\
$50 \mathrm{ppm}$ & $0,44 \mathrm{abc}$ & $2,53 \mathrm{a}$ & $4,96 \mathrm{ab}$ \\
$25 \mathrm{ppm}$ & $0,24 \mathrm{bc}$ & $2,30 \mathrm{a}$ & $1,68 \mathrm{c}$ \\
$0 \mathrm{ppm}$ & $0,20 \mathrm{c}$ & $1,75 \mathrm{a}$ & $2,81 \mathrm{bc}$ \\
\hline
\end{tabular}

JAP dan PAP mempunyai korelasi $\left(\mathrm{r}^{2}\right)$ sebesar 0,74. Nilai ini menunjukkan bahwa terdapat hubungan yang cukup kuat antara penambahan JAP akan diikuti dengan peningkatan PAP. Persamaan matematik untuk hubungan konsentrasi IBA terhadap JAP dan PAP masing-masing adalah Yjap $=0,011 \mathrm{x}+$ $1,912\left(\mathrm{r}^{2}=0,85\right)$ dan Ypap $=0,032 \mathrm{x}+2,366$ $\left(r^{2}=0,62\right)($ Gambar 2).

Peningkatan panjang akar primer sebesar $70 \%$ pada perlakuan 75 ppm dibandingkan 25 ppm akan mempertinggi tingkat keberhasilan pertumbuhan pasca penyapihan, karena akar primer ini akan membantu memperkokoh pertumbuhan semai pada fase pertumbuhan. Pemberian IBA dengan konsentrasi tinggi pada prinsipnya tidak menyebabkan keracunan terhadap stek pucuk dan dapat digunakan dalam kisaran konsentrasi yang cukup lebar (Hartmann \& Kester, 1983). Penelitian terkait di antaranya adalah penggunaan konsentrasi IBA sebesar 10.800 ppm pada tanaman S. macrocpylla yang menghasilkan persen berakar sebesar $89 \%$ dengan jumlah akar sebanyak 6,3 (Lo, 1985). Kadar auksin yang optimal untuk merangsang pembentukan primordial akar biasanya terlalu tinggi untuk merangsang perpanjangan akar (Wetherell, 1982).

Hormon secara alami sudah ada pada tumbuhan, namun ZPT tetap diberikan pada stek dengan tujuan meningkatkan kemampuan berakar stek, mempercepat proses pertumbuhan akar, meningkatkan jumlah dan kualitas akar, serta mengurangi keragaman jumlah dan kualitas perakaran stek. Pemberian ZPT IBA pada konsentrasi yang berbeda untuk stek pucuk dapat berdasarkan jenis tanaman dan umur ataupun kondisi materi, termasuk di antaranya yang telah dilakukan pada Shorea leprosula (Aminah et al., 1995), S. macrophylla (Lo, 1985), S. parvifolia dan S. macroptera (Aminah, Nor Hasnita, \& Hamzah, 2006).

\section{B. Akar Sekunder}

Akar sekunder merupakan akar yang tumbuh dan berkembang sepanjang akar primer. Fungsi dari akar ini adalah membantu semai dalam penyerapan unsur hara. Hasil ANOVA menunjukkan bahwa pemberian IBA pada berbagai konsentrasi dapat memberikan hasil yang berbeda nyata untuk variabel JAS $(P<$ $0,05)$, sedangkan untuk variabel PAS hasil yang diperoleh tidak berbeda nyata $(P>0,05)$ (Tabel $3)$. 


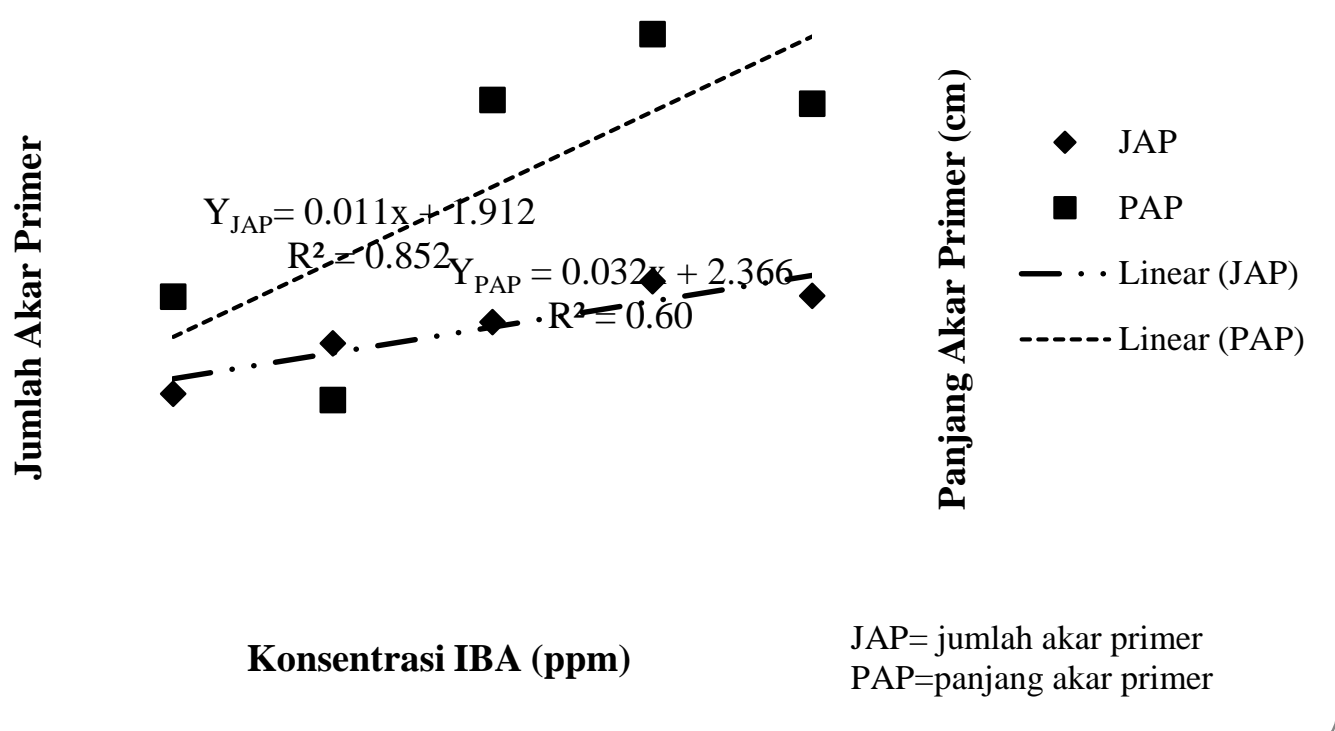

Gambar 2. Hubungan konsentrasi IBA terhadap jumlah dan panjang akar primer

Tabel 3. Anova pengaruh konsentrasi IBA terhadap jumlah dan panjang akar sekunder stek pucuk S. platyclados

\begin{tabular}{|c|c|c|c|c|c|}
\hline \multirow{2}{*}{ Sumber Variasi } & \multirow{2}{*}{$\mathrm{db}$} & \multicolumn{2}{|l|}{ JAS } & \multicolumn{2}{|l|}{ PAS } \\
\hline & & KT & Sig. & KT & Sig. \\
\hline Konsentrasi IBA & 4 & 229,22 & $3,67^{*}$ & 2,17 & $1,99 \mathrm{~ns}$ \\
\hline Eror & 19 & 62,45 & & 1,08 & \\
\hline
\end{tabular}

Keterangan: "=signifikan pada $\mathrm{p}<0,05$; ns= tidak signifikan pada $\mathrm{p}<0,05$; JK=jumlah kuadrat; JAS=jumlah akar sekunder; PAS=panjang akar sekunder

Hasil uji lanjut terhadap perlakuan yang diujikan menunjukkan bahwa perlakuan IBA 75 ppm memberikan jumlah akar terbanyak yaitu
20,14; sedangkan perlakuan IBA 25 ppm menghasilkan jumlah akar paling sedikit yaitu 2,05 (Tabel 4.)

Tabel 4. Uji lanjut pengaruh konsentrasi IBA terhadap jumlah akar sekunder stek pucuk S. platyclados

\begin{tabular}{lll}
\hline Konsentrasi IBA & JAS & PAS $(\mathrm{cm})$ \\
\hline $100 \mathrm{ppm}$ & $12,59 \mathrm{ab}$ & $1,98 \mathrm{a}$ \\
$75 \mathrm{ppm}$ & $20,14 \mathrm{a}$ & $1,32 \mathrm{a}$ \\
$50 \mathrm{ppm}$ & $14,80 \mathrm{a}$ & $2,22 \mathrm{a}$ \\
$25 \mathrm{ppm}$ & $2,05 \mathrm{~b}$ & $0,83 \mathrm{a}$ \\
$0 \mathrm{ppm}$ & $16,38 \mathrm{a}$ & $0,70 \mathrm{a}$ \\
\hline
\end{tabular}

Keterangan: rerata yang diikuti dengan huruf yang sama tiap kolomnya tidak berbeda nyata pada taraf uji $\mathrm{p}<0,05$

Jumlah akar sekunder (JAS) yang berkembang pada stek pucuk berkorelasi positif dengan jumlah akar primer. Tabel 4 menunjukkan bahwa keberadaan jumlah akar sekunder pada setiap akar primer bervariasi mulai 2,05 sampai dengan 20,14. Konsentrasi IBA $50 \mathrm{ppm}$ menghasilkan nilai PAS yang terbaik, yaitu $2,22 \mathrm{~cm}$, sedangkan yang terendah adalah perlakuan $25 \mathrm{ppm}(0,83 \mathrm{~cm})$. Penambahan konsentrasi IBA pada stek pucuk akan 
meningkatkan jumlah akar yang dihasilkan. Hal ini sesuai dengan (Aminah et al., 1995) yang melaporkan bahwa pemberian IBA $20 \mu \mathrm{g}$ akan menghasilkan rerata jumlah akar sebesar $62 \%$ dibandingkan kontrol. Pada tingkat konsentrasi IBA 100 ppm stek pucuk meranti putih (Shorea montigena) mempunyai berat kering akar yang lebih besar dan telah mempunyai akar-akar lateral (Irwanto, 2001).

Pertambahan JAS dan PAS mempunyai hubungan yang lemah, ditunjukkan dengan nilai $\mathrm{R}^{2}$ sebesar 0,25 . Hal ini mengindikasikan bahwa bertambahnya JAS tidak secara nyata diikuti dengan bertambah panjangnya PAS. Persamaan polynomial untuk variabel JAS dan PAS pada berbagai konsentrasi IBA sampai dengan 100 ppm adalah $\mathrm{YJAS}=-0,000 \mathrm{x}^{3}+0,032 \mathrm{x}^{2}-1,174 \mathrm{x}$ $+15,96\left(\mathrm{r}^{2}=0,935\right)$ dan YPAS $=-0,000 \mathrm{x}^{2}+0,026 \mathrm{x}$ $+0,624\left(\mathrm{r}^{2}=0,567\right)($ Gambar 3). Di sisi lain hubungan yang lemah juga ditunjukkan antara JAP dengan JAS yang mempunyai korelasi $\left(\mathrm{R}^{2}\right)$ sebesar 0,23. Sementara itu, kekuatan hubungan antara JAP dengan PAS; PAP dengan JAS; dan PAP dengan PAS relatif tinggi dengan nilai korelasi $\left(\mathrm{R}^{2}\right)$ untuk masing-masing adalah 0,62 ; 0,76 dan 0,73 .

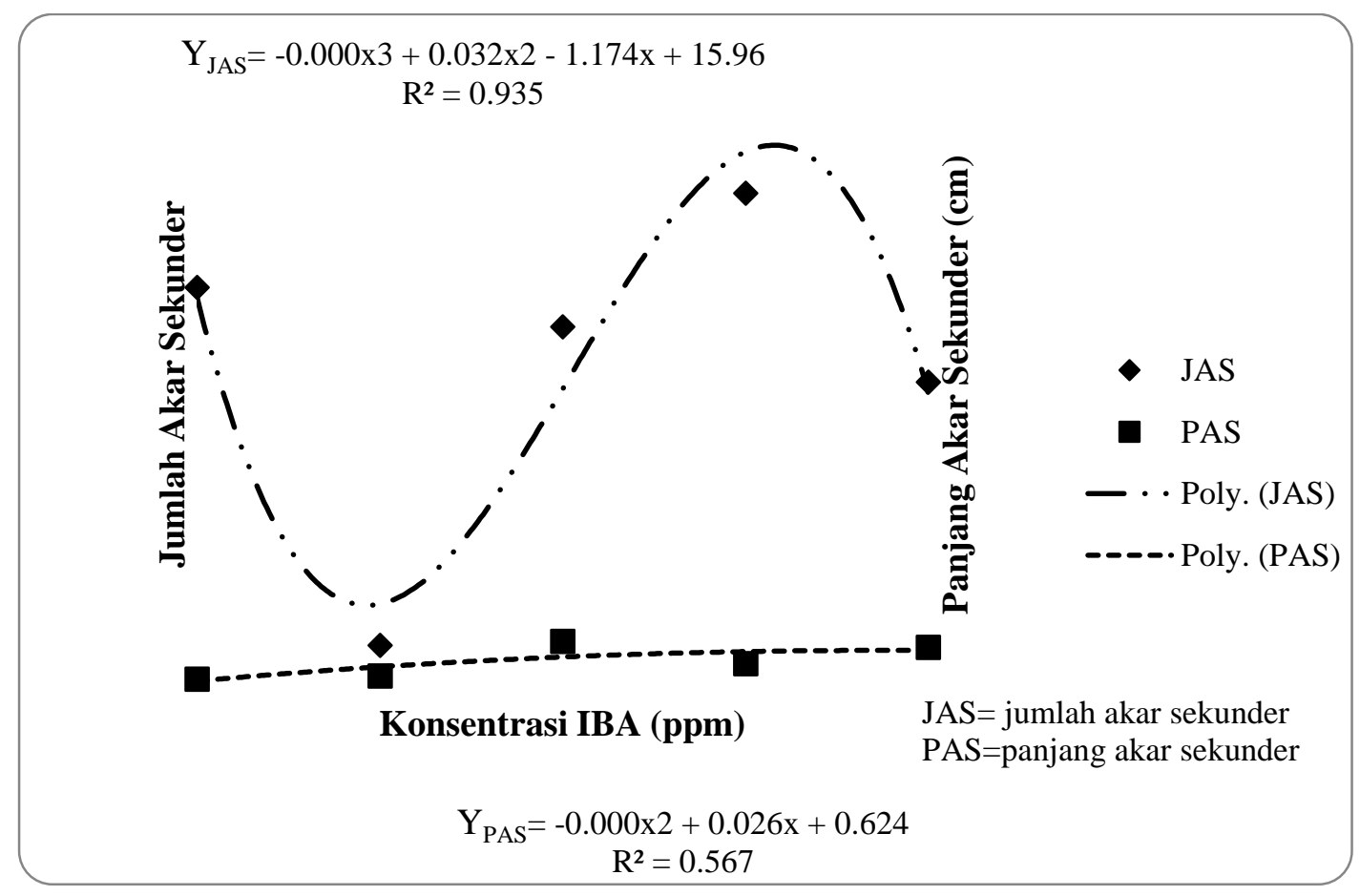

Gambar 3 . Hubungan konsentrasi IBA terhadap jumlah dan panjang akar sekunder

Di sisi lain, pembangunan hutan tanaman meranti komersiil perlu didukung dengan berbagai kegiatan penelitian yang antara lain adalah uji-spesies, uji-keturunan, yang akan menghasilkan jenis dan klon meranti unggul dan diikuti dengan pembangunan kebun pangkas dari klon meranti terpilih (Na'iem, 2015; Naiem, Widiyatno, \& Al-Fauzi, 2014). Untuk itu kajian perbanyakan vegetatif ini sangat berkorelasi dengan penelitian uji-keturunan S. platyclados yang akan menghasilkan famili unggul. Seleksi famili unggul ini akan diikuti dengan pembangunan kebun pangkas untuk menghasilkan stek pucuk guna mewujudkan hutan tanaman S. platyclados yang produktif, kompetitif, efisien, sehat dan lestari.

\section{KESIMPULAN}

Berdasarkan beberapa temuan di atas, konsentrasi IBA 75 ppm merupakan konsentrasi yang direkomendasikan untuk diaplikasikan dalam program pengakaran stek pucuk $S$. platyclados. Hal ini didasarkan pada hasil analisis yang menunjukan bahwa dosis $75 \mathrm{ppm}$ 
telah dapat menghasilkan kemampuan berakar, jumlah dan panjang akar primer; serta jumlah dan panjang akar sekunder yang lebih baik dibandingkan perlakuan konsentrasi lainnya yang diujikan. Untuk itu maka penelitian ujiketurunan untuk mendapatkan keturunan yang unggul, serta pembangunan kebun pangkas dari klon-klon yang telah terbukti unggul merupakan hal yang sangat penting untuk dilaksanakan.

\section{UCAPAN TERIMA KASIH}

Penulis menyampaikan terima kasih kepada Kemenristek Dikti yang telah memberikan dukungan dana melalui Hibah Penelitian Multi Tahun sehingga penelitian ini dapat dilaksanakan dan diselesaikan. Ucapan terima kasih juga kami sampaikan kepada PT. Sari Bumi Kusuma Kalimantan Tengah yang telah memberikan dukungan, bantuan, saran dan masukan dalam pelaksanaan dan penyelesaian penelitian ini.

\section{DAFTAR PUSTAKA}

Abidin, Z. (1983). Dasar-dasar pengetahuan tentang zat pengatur tumbuh: auxin, gibberellin, cytokinin, ethylene, inhibitors. Angkasa, Bandung.

Aminah, H., Dick, J. M., Leakey, R. R. B., Grace, J., \& Smith, R. I. (1995). Effect of indole butyric acid (IBA) on stem cuttings of Shorea leprosula. Forest Ecology and Management, 72(2), 199-206. https://doi.org/https://doi.org/10.1016/03781127(94)03461-5

Aminah, H., Nor Hasnita, R. M. N., \& Hamzah, M. (2006). Effects of indole butyric acid concentrations and media on rooting of leafy stem cuttings of Shorea parvifolia and Shorea macroptera. Journal of Tropical Forest Science, 18(1), 1-7.

Appanah, S., \& Weinland, G. (1993). Planting quality timber trees in Peninsular Malaysia: a review. Kuala Lumpur, Malaysia: Forest Research Institute Malaysia. Retrieved from https://www.cabdirect.org/cabdirect/abstract/ 19960608868

Ashton, P. S. (1982). Flora Indo-Malayana. Ser. I, 9(2), 237-552.
Hartmann, H. T., \& Kester, D. E. (1983). Plant Propagation: Principles and Practices (4th ed.). New Jersey: Eaglewood Cliffs.

Hartmann, H. T., Kester, D. E., \& Davies, F. T. (1990). Plant propagation: Principles and practices. New Jersey: Regents Hall.

Hunt, M. A., Trueman, S. J., \& Rasmussen, A. (2011). Indole-3-butyric acid accelerates adventitious root formation and impedes shoot growth of Pinus elliottii var. elliottii $\times P$. caribaea var. hondurensis cuttings. New Forests, 41(3), 349-360. https://doi.org/10.1007/s11056010-9227-7

Irwanto. (2001). Pengaruh hormon iba (indole butyric acid) terhadap persen jadi stek pucuk meranti putih (Shorea montigena), 1-27.

Lo, Y.-N. (1985). Root initiation of Shorea macrophylla cuttings: Effects of node position, growth regulators and misting regime. Forest Ecology and Management, 12(1), 43-52. https://doi.org/https://doi.org/10.1016/03781127(85)90135-5

Momose, Y. (1978). Vegetative propagation of Malaysian trees. Malaysian Forester, 41(3), 219-223.

Na'iem, M. (2015). Peningkatan produktivitas hutan dari rotasi ke rotasi. In D. Prehaten, A. Syahbudin, \& R. D. Andiyani (Eds.), Pembaruan Silvikultur untuk Mendukung Pemulihan Fungsi Hutan menuju Ekonomi Hijau Prosiding Seminar Nasional Silvikultur II Tahun 2014 (pp. 3-11). Yogyakarta.

Naiem, M., Widiyatno, \& Al-Fauzi, M. Z. (2014). Progeny Test of Shorea Leprosula as Key Point to IncreaseProductivity of Secondary Forest in PT. Balik Papan Forest Industries, East Kalimantan, Indonesia. Procedia Environmental Sciences, 20 (December 2014), 816-822. https://doi.org/10.1016/j.proenv.2014.03.099

Newman, M. F., Burgess, P. F., \& Whitmore, T. C. (1996a). Manuals of Dipterocarps for Foresters: Borneo Island Light Hardwoods. Edinburgh: CIFOR and Royal Botanic Garden.

Newman, M. F., Burgess, P. F., \& Whitmore, T. C. (1996b). Manuals of Dipterocarps for Foresters: Sumatra Island Light Hardwoods. Edinburgh: CIFOR and Royal Botanic Garden.

Numata, S., Suzuki, R. O., Nishimura, S., Naito, Y., Konuma, A., Tsumura, Y., ... Supardi, M. N. N. (2012). Fruiting behavior of dipterocarps in two consecutive episodes of general flowering 
in a Malaysian lowland rain forest. Journal of Forest Research, 17(4), 378-387. https://doi.org/10.1007/s10310-011-0308-z

Numata, S., Yasuda, M., Okuda, T., Kachi, N., \& Noor, N. S. M. (2003). Temporal and spatial patterns of mass flowerings on the Malay Peninsula. American Journal of Botany, 90(7), 1025-1031.

https://doi.org/10.3732/ajb.90.7.1025

Sasaki, S. (1980). Growth and Storage of Bare-Root Planting Stock of Dipterocarps with Special Reference to Shorea talura. Malaysian Forester, 43(2), 144-160. Retrieved from https://www.cabdirect.org/cabdirect/abstract/ 19810670947
Srivastava, P. B. L., \& Manggil, P. (1981). Vegetative Propagation of Some Dipterocarps by Cuttings. Malaysian Forester, 44(2 \& 3), 301313.

Subiakto, A. (2006). Irregular Flowering Pattern. (Silviculture Systems of Indonesia's Dipterocarps Forest Management A Lesson Learned No. Technical Report: ITTO Project PD 41/00 Rev. 3 (F,M)). Yogyakarta.

Wetherell, D. F. (1982). Propagasi tanaman secara in vitro (Terjemahan). Bandung: ITB.

Widiyatno, W., Soekotjo, S., Naiem, M., Purnomo, S., \& Setiyanto, P. E. (2014). Early performance of 23 dipterocarp species planted in loggedover rainforest. Journal of Tropical Forest Science, 26(2), 259-266. 